\section{Title: $\quad$ RESEARCH FOR NEW UAV CAPABILITIES}

Author(s):

Submitted to:

Gregory H. Canavan, DDP

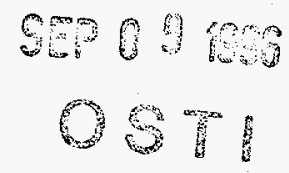

For discussions outside the Laboratory

Date: July 1996
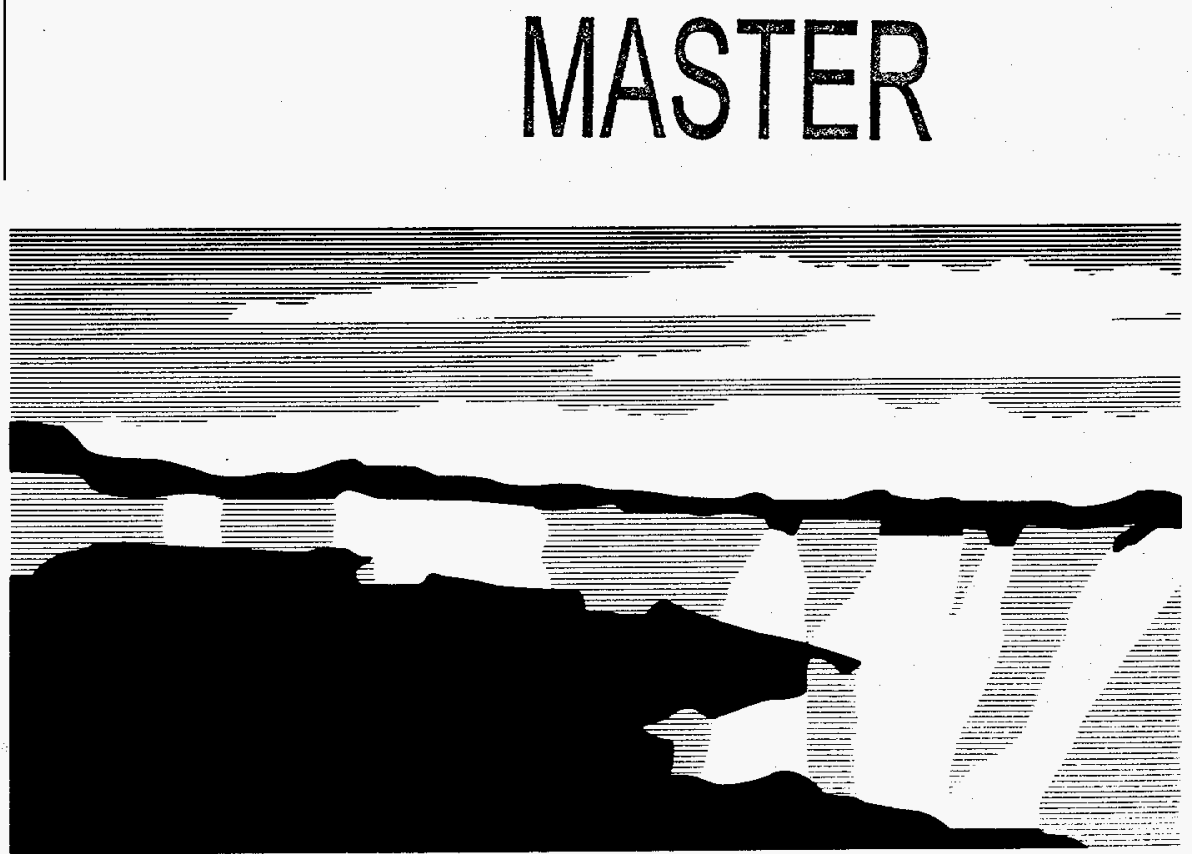

Los Alamos National Laboratory, an affirmative action/equal opportunity employer, is operated by the University of California for the U.S. Department of Energy under contract W-7405-ENG-36. By acceptance of this article, the publisher recognizes that the U.S. Government retains a nonexclusive, royalty-free license to publish or reproduce the published form of this contribution, or to aliow others to do so, for U.S. Government purposes. The Los Alamos National Laboratory requests that the publisher identify this article as work performed under the auspices of the U.S. Department of Energy. 


\section{DISCLAIMER}

Portions of this document may be illegible in electronic image products. Images are produced from the best available original document. 


\section{DISCLAIMER}

This report was prepared as an account of work sponsored by an agency of the United States Government. Neither the United States Government nor any agency thereof, nor any of their employees, makes any warranty, express or implied, or assumes any legal liability or responsibility for the accuracy, completeness, or usefulness of any information, apparatus, product, or process disclosed, or represents that its use would not infringe privately owned rights. Reference herein to any specific commercial product, process, or service by trade name, trademark, manufacturer, or otherwise does not necessarily constitute or imply its endorsement, recommendation, or favoring by the United States Government or any agency thereof. The views and opinions of authors expressed herein do not necessarily state or reflect those of the United States Government or any agency thereof. 


\title{
RESEARCH FOR NEW UAV CAPABILITIES
}

\author{
Gregory H. Canavan and Ray Leadabrand
}

Mission needs presented Mission Needs Statement, CR, 1/90, SR 11/88; Operational Requirements Document, JCS Pub 3-55.1; IntelCtr Field Manual 34-35-2, 6/95; and IntelCenter, CONOPS 9/95 can be used to define and prioritize missions and applications.

Findings: UAV performance could be enhanced greatly by modest research programs in a few key mission areas. The attached chart shows that current technological opportunities correlate well with priority missions. Performing the R\&D for priority applications would also provide the technology base for other applications.

RSTA/BDA in daylight could benefit greatly from lighter, cheaper EO sensors in the near term and mm wave radiometers in the long term. Near term passive imagery options include large format CCD focal planes and hyper spectral imagery. In the longer term, night capability could benefit from much lighter and cheaper EO sensors and FLIRs. Near term needs in active imagery include lighter SARs with MTI and laser radars for TUAV and smaller UAVs with extensions of current developments. In the longer term, Fopen radars (VLF SARs for leaf and ground penetration) and SAR ID interpretation could greatly extend resolution and detection.

Communication relay could be significantly improved in the near term with greater bandwidth and commonalty and in the long term with covert, LPI, AJ communication, improved connectivity and link quality.

Intelligence collection could be greatly improved in the near term through the integration of developed SIGINT sensors and in the long term through the addition of COMINT and ESM sensors. MASINT could be provided in the longer term through fielding of the RSTA \& BDA imaging sensors discussed above.

Meteorological capabilities would be significantly improved in the near term by the direct measurement of winds aloft and in the longer term through the addition of Doppler radars for synoptic measurements.

SOF capability could be extended through additional stealth, improved LPI, \& covert communications relays. On a longer time scale, SOF capabilities would be enhanced by improved navigational aids adequate for the delivery of precision weapons.

EW \& offensive IW (electronic and information warfare) would be extended by light electronics \& offensive IW radiofrequency $\mathrm{DEW}$ packages. 
NBC (nuclear, biological, and chemical) warfare countermeasures would be enhanced by the deployment of small sensors to detect \& track chemical \& biological agents and the development of advanced concepts for the detection of nuclear materials.

Mine detection would be advanced by the development and down selection of infrared (ASTAMIDS) laser radars, and foliage penetrating radars (Fopen).

Search \& Rescue(combat), needs lighter, deployed SIGINT sensors, covert communication, \& the improved RSTA/BDA imaging systems discussed above.

Deception \& Psyops could benefit from the offensive IW \& EW sensors discussed above.

Rear Area Security/Civil Agencies could be improved by the SIGINT \& imagery sensors above 


\section{CROSSCUTTING ISSUES}

GPS. The top priority is the development of hardware and protocols to protect our use. That is followed closely by the need to develop means to deny its use to the enemy.

Survivability could be improved in the near term by the reduction of acoustic and infrared signatures. In the mid term it could be further improved by, LPI links, combat ID, greater autonomy for low altitude evasive maneuvers; and greater speed. In the long term it could be maintained by reducing radar observables. Ultimately it appears necessity to greatly reduce UAV size, weight, and cost for effectiveness against evolving defenses.

Improved propulsion. Gas turbine engines with more power and less weight and volume should be prototyped and retrofitted into Hunter, TUAV, and Predator to extend range and increase payload flexibility.

Autonomy is needed for flexible missions and survivability. Common designs should be developed, retrofitted, and used on future UAVs.

Low cost/expendable UAVs should be prototyped, flown, and competed for future TUAV modifications, and weaponized.

VTOL UAV. Select \& fly prototypes and compete for follow on to TUAV.

Stealth. Develop survivability measures discussed above; prototype; and evaluate new, multiple missions.

Conclusions: Improved sensors, communications will enhance near term cost effectiveness. Improved engines, platforms, and stealth will improve long term effectiveness.

Recommendations: Mission priorities and technological readiness should determine R\&D emphases. They are largely consistent. Improved EO \& hyper spectral sensors are needed for near-term range \& discrimination. Lighter SAR \& MTI are needed for all weather \& high tasking rates. SIGINT and EW are needed for battlefield awareness. Communications relays with greater bandwidth and LPI are needed for connectivity. Mine detection sensors are needed for beachhead and inland operations at all levels. Research on radically improved FLIRs is needed. Improved propulsion is required for all missions. Survivability: through acoustic, IR, and radar signature reduction is needed to improve the effectiveness of all missions. 


\section{P3I UPGRADES}

$\mathrm{P}^{3}$ I upgrades enable a number of additional Force XXI capabilities in addition to the RSTA/BDA missions discussed above, which are described in Mission Needs Statement, CR, 1/90, SR 11/88; Operational Requirements Document, JCS Pub 3-55.1; IntelCtr Field Manual 34-35-2, 6/95; and IntelCenter, CONOPS 9/95.

SIGINT (signal) and MASINT (measurement) intelligence collection sensors can greatly improve battlefield awareness and provide prompt, synoptic assessments of the order of battle.

Electronic Warfare (EW) can be improved by lightweight electronics packages under development and research on radiofrequency directed energy warfare (DEW) and information warfare (IW) packages.

Meteorology can be improved by measurements of winds aloft and the deployment of Doppler radars for precision, wide area measurements of winds and weather.

NBC (nuclear, biological, and chemical) reconnaissance. UAVs could carry a number of small sensors to detect and track chemical and biological agents, if lightweighted by a factor of two. Advanced concepts are needed for the detection of nuclear materials, for which the detection ranges of current sensors are fractions of a kilometer.

Special Operations Forces (SOF) support would be enhanced by stealthy UAVs as communications relays for low probability of intercept (LPI) and covert communications and as platforms for delivery of precise weapons.

Minefield detection. would be fundamentally advanced by the down-selection, development and deployment of infrared (ASTAMIDS), laser radar, and foliage penetration (Fopen) radar s.

Combat Search \& Rescue would be enhanced by the deployment of the SIGINT sensors, covert communications, and RSTA/BDA systems discussed above.

Deception and Psychological Operations could be advanced by the offensive IW \& EW systems above.

Rear Area Security and Support to Civil Agencies. could be greatly improved by rear-area deployment of UAVs with the SIGINT and imagery sensors discussed above.

Weapons delivery would be provided by combining existing munitions with the precision RSTA/BDA sensors and robust communications links discussed above with improved GPS, digital maps, and enhanced survivability through reduced acoustic, infrared, and radar signatures, which would provide effective, prompt, precision strike against fixed and mobile targets without risk of life. 


\section{RESEARCH FOR NEW UAV CAPABILITIES}

CAPABILITIES*

- Imagery for RSTABBDA

- Passive imagery (Day/Night)

- Active imagery

- COMM relay

- Intel collection

- MASINT

- Meterological

- SOF

- EW

- NBC

- Mine detection

Search \& rescue (combat)

Deception \& Psyops

Rear area security/Civ ag
NEAR TERM

- Lighter, cheaper EO sensor

Large CCD focal planes, hyperspectral imagery

- Lighter SAR, add MTI, laser radar Bandwidth, commonalty

- SIGINT sensors

- Direct winds aloft

- Stealth, comm relay, LPI \& covert (above)

- Light electronics \& DEW for offensive IW

- Small sensors to detect \& track chemical \& biological agents

- ASTAMIDS, laser radars, Fopen radar above

SIGINT, covert comm \& imagery above

Offensive IW \& EW above

SIGINT \& imagery sensors above

\section{LONGER TERM}

- MM radiometer

Much lighter, cheaper EO/FLIR

- Fopen radar, SAR target ID, multi-statics Covert, LPI, AJ, connectivity, quality

- COMINT, ESM

RSTA/BDA imaging sensors above

- Doppler radar

- Weapons

Advanced concepts for nuclear material
*Mission Needs Stmt

CR, 1/90, SR 11/88
Operational Requirements Document JCS Pub 3-55.1
IntelCtr Field Ctr Manual 34-35-2,6/95

IntelCenter CONOPS 9/95 


\section{RESEARCH FOR NEW UAV CAPABILITIES (CONT.)}

\section{CROSSCUTTING ISSUES}

CAPABILITIES

- GPS

- Survivability

- Improved propulsion

- Autonomy

- Low costlexpendable

UAV Fly prototypes

- VTOL UAV

- Stealth
NEAR TERM

Protect use--deny to enemy

Acoustic, IR, radar obs; combat ID, LPI link

Prototype gas turbine engine

Common design

Select \& fly prototypes

Survivability measures above, fly prototypes
LONGER TERM

Size, weight, cost; autonomy; speed LO Retrofit into Hunter, TUAV, Predator Use on future UAVs

Compete TUAV+, weaponize

Compete with TUAV+

Evaluate new, multiple missions

FINDINGS: UAV performance greatly enhanced by modest research. Technological opportunities correlate with priority missions. R\&D for priority applications also provides basis for growth missions.

CONCLUSIONS: Improved sensors and communications enhance near term cost effectiveness. Improved engines, platforms, and stealth improve long term effectiveness. 